\title{
Striatal Monoamine Terminals in Lewy Body Dementia and Alzheimer's Disease
}

\author{
Sid Gilman, MD, FRCP, ${ }^{1}$ Robert A. Koeppe, PhD, ${ }^{2}$ Roderick Little, PhD, ${ }^{3}$ Hyonggin An, MS, ${ }^{3}$ \\ Larry Junck, MD, ${ }^{1}$ Bruno Giordani, PhD, ${ }^{4}$ Carol Persad, PhD, ${ }^{4}$ Mary Heumann, BA, ${ }^{1}$ and Kris Wernette, $\mathrm{RN}^{1}$
}

\begin{abstract}
We used positron emission tomography (PET) with $(+)-\left[{ }^{11} \mathrm{C}\right]$ dihydrotetrabenazine $\left([+]-\left[{ }^{11} \mathrm{C}\right] \mathrm{DTBZ}\right)$ to examine striatal monoaminergic presynaptic terminal density in 20 patients with dementia with Lewy bodies (DLB), 25 with Alzheimer's disease (AD), and 19 normal elderly controls. Six DLB patients developed parkinsonism at least 1 year before dementia (DLB/PD) and 14 developed dementia before parkinsonism or at about the same time (DLB/AD). Striatal mean binding potential was decreased by 62 to $77 \%$ in the DLB/PD group and 45 to $67 \%$ in the DLB/AD compared to AD and control. Binding was lower in the DLB/PD group than the DLB/AD, but the differences reached only marginal significance in the caudate nucleus. No differences were found between $\mathrm{AD}$ and control groups though a few $\mathrm{AD}$ patients had binding values below the range of the controls. Subsequent neuropathological examination in one AD patient revealed both $\mathrm{AD}$ and DLB changes despite the absence of clinical parkinsonism. Both DLB groups had an anterior to posterior binding deficit gradient relative to controls, largest in posterior putamen, smaller in anterior putamen, smallest in caudate nucleus. The DLB/AD group showed significant binding asymmetry only in posterior putamen. We conclude that PET with $(+)-\left[{ }^{11} \mathrm{C}\right] \mathrm{DTBZ}$ differentiates DLB from $\mathrm{AD}$, and decreased binding in $\mathrm{AD}$ may indicate subclinical DLB pathology in addition to $\mathrm{AD}$ pathology.
\end{abstract}

Ann Neurol 2004;55:774-780

Dementia with Lewy bodies (DLBs) may be the second most frequent cause of dementia in the elderly, accounting for 15 to $25 \%$ of cases. ${ }^{1}$ Alzheimer's disease $(\mathrm{AD})$ is the most frequent cause and is responsible for 50 to $60 \%$ of dementia cases in the elderly. The neuropathological features of DLB include widespread neuronal degeneration with deposition of Lewy bodies and Lewy neurites, which contain $\alpha$-synuclein as a major filamentous component. ${ }^{2}$ Substantial neuronal loss occurs in the substantia nigra and nigrostriatal projections are decreased. Many cases of DLB show concomitant neuropathological changes of AD. ${ }^{1,3}$ Despite this overlap, DLB appears to be a distinctive clinicopathological entity characterized as an $\alpha$-synucleinopathy along with idiopathic Parkinson's disease (PD) and multiple system atrophy. ${ }^{1,4}$ Lewy bodies contain other abnormal proteins in addition to $\alpha$-synuclein, notably parkin. $^{5}$

The central features of DLB include parkinsonism with a progressive dementia, and the latter includes deficits in memory, attention, language, psychomotor performance, executive functioning, and visuospatial and visuoconstructive abilities. ${ }^{6}$ Perceptual and affec- tive disturbances appear more frequently in DLB than $\mathrm{AD}$ and consist of recurrent visual hallucinations, ${ }^{7,8}$ delusions, ${ }^{8}$ depression, ${ }^{7}$ and agitation. ${ }^{9}$ Sensitivity to neuroleptic drugs is prominent. ${ }^{10}$ Both bradykinesia and rigidity occur frequently, ${ }^{8}$ but resting tremor is rare $^{8,10}$ The parkinsonian features in DLB are more symmetrical than in PD. ${ }^{10}$ Consensus criteria have been developed for the clinical diagnosis of DLB, ${ }^{11}$ but several prospective and retrospective studies of these criteria generally have shown limited accuracy. With neuropathological findings as the gold standard, ${ }^{12-17}$ these studies have shown the sensitivity of the criteria to range from $31 \%{ }^{17}$ to $83 \%{ }^{16}$ and the specificity from $64 \%{ }^{15}$ to $100 \% .^{17}$

Because disease-modifying treatments soon may become available for neurodegenerative dementias, early diagnosis becomes increasingly important. To this end, we initiated a positron emission tomography (PET) study in DLB and AD using $(+)-\left[{ }^{11} \mathrm{C}\right]$ dihydrotetrabenazine $\left([+]-\left[{ }^{11} \mathrm{C}\right] \mathrm{DTBZ}\right)$ to examine nigrostriatal projections. $(+)-\left[{ }^{11} \mathrm{C}\right] \mathrm{DTBZ}$ binds to the monoaminergic vesicular transporter type 2 and is useful for evaluating nigrostriatal projections. The study was designed to detect
From the ${ }^{1}$ Department of Neurology, Division of Nuclear Medicine and Departments of ${ }^{2}$ Radiology, ${ }^{3}$ Biostatistics, and ${ }^{4}$ Psychiatry, University of Michigan, Ann Arbor, MI.

Received Aug 11, 2003, and in revised form Dec 8. Accepted for publication Feb 10, 2004.

Published online Apr 27, 2004, in Wiley InterScience (www.interscience.wiley.com). DOI: 10.1002/ana.20088
Address correspondence to Dr Gilman, Department of Neurology, University of Michigan Health System, 1500 E. Medical Center Drive, Ann Arbor, MI 48109-0316. E-mail sgilman@umich.edu 
differences in biochemistry, relate the differences to clinical presentation, and determine whether this ligand would be helpful in differentiating cases, particularly in the early stages. We report here the results of studies with PET and (+)-[ $\left[{ }^{11} \mathrm{C}\right] \mathrm{DTBZ}$ in patients meeting consensus for $\mathrm{DLB},{ }^{11}$ patients meeting $\mathrm{Na}$ tional Institute of Neurological Communicative Disorders and Stroke Alzheimer's Disease and Related Disorders Association (NINDS-ADRDA) criteria for $\mathrm{AD},{ }^{18}$ and a group of elderly normal control subjects. We selected patients with advanced disorders with the intention of examining patients in the early stages of these disorders in a later study.

\section{Subjects and Methods}

\section{Subject Selection}

The institutional review board of the University of Michigan approved the investigation. We obtained informed consent from all participants or their caregivers. We studied 64 subjects, including 25 with $\mathrm{AD}$ aged $69.3 \pm 9.1$ years (mean \pm standard deviation; range, 52-85 years, 7 men and 18 women); 20 with DLB aged $72.8 \pm 7.2$ years (range, 54-81 years; 15 men and 5 women); and 19 normal elderly controls aged $69.1 \pm 7.6$ years (range, 55-86 years; 10 men and 9 women). We used NINCDS-ADRDA criteria for the diagnosis of $\mathrm{AD}^{18}$ and consensus criteria ${ }^{11}$ for the diagnosis of probable DLB. We divided the DLB cases into two groups, six who developed parkinsonian features at least 1 year before dementia appeared (DLB/PD) and 14 who developed dementia before parkinsonism or at about the same time (DLB/AD).

\section{Subject Evaluations}

All subjects were evaluated with general physical and neurological examinations, neuropsychological evaluations, magnetic resonance (MR) scans, PET scans, and appropriate laboratory studies to ensure the accuracy of the clinical diagnosis. None of the subjects had a history of disturbances in consciousness, serious head injury, stroke, or abuse of alcohol or drugs. All subjects had a modified Hachinski score of less than $4^{19}$ and no focal abnormality in computed tomography or MR scan except for "bright spots" or mild generalized atrophy. All subjects had adequate hearing and visual acuity to complete the studies, including neuropsychological evaluations. In the patient groups, there were no systemic diseases or other brain diseases that could account for their neurological deficits. We evaluated all medications that the patients were taking and ensured that cognitive impairment persisted after withdrawal of medications that might impair cognition. If depressive features were found, we made certain that the dementia did not reverse with antidepressants. Thirteen DLB patients were taking carbidopa/L-dopa, but this medication has no effect on binding of $(+)-\left[{ }^{11} \mathrm{C}\right] \mathrm{DTBZ}$. The laboratory studies included a complete blood count, sedimentation rate, chemical profile, urinalysis, serological test for syphilis, thyroid studies, and serum levels of vitamin $B_{12}$ and folic acid. These studies were normal or judged to be clinically insignificant. Although $(+)-\left[{ }^{11} \mathrm{C}\right] \mathrm{DTBZ}$ binding is not known to be altered by medications, medications that might influence dopaminergic presynaptic neurons were discontinued 4 weeks before the PET study.

\section{Neuropsychological Testing}

We assessed general mental status and orientation with the Mini-Mental State Examination (MMSE), ${ }^{20}$ attention with the Digit Span test, ${ }^{21}$ language with the Multilingual Aphasia Examination Visual Naming Test, ${ }^{22}$ visual-spatial ability with the Visual Form Discrimination Test, ${ }^{23}$ memory with the Hopkins Verbal Learning Test-Revised, ${ }^{24}$ and family ratings of general motor ability with the motor subscale of the Inventory of Psychic and Somatic Complaints-Elderly. ${ }^{25}$

\section{Positron Emission Tomography Imaging}

We injected $18 \pm 1.8 \mathrm{mCi}$ of $(+)-\left[{ }^{11} \mathrm{C}\right] \mathrm{DTBZ}$ to measure the density of striatal monoaminergic terminals. ${ }^{26,27}$ This stereospecific ligand has a high affinity $\left(\mathrm{K}_{\mathrm{D}}=1 \mathrm{nM}\right)$ for the vesicular monoamine transporter type 2 (VMAT2) site. The radiotracer was administered as a partial bolus $(55 \%$ of the injected dose) followed by continuous infusion (the remaining $45 \%$ ) over the duration of the PET study. In the course of this investigation, we replaced our PET scanner. Consequently, we studied 25 subjects with a Siemens/CTI ECAT Exact-47 scanner (10 DLB patients, $9 \mathrm{AD}$ patients, and 6 normal controls) and 39 subjects with a Siemens/CTI ECAT Exact HR+ scanner (10 DLB patients, $16 \mathrm{AD}$ patients, and 13 normal controls). All scans were performed in threedimensional mode with the interplane septa retracted. Measured attenuation correction was performed from a 6 to 10 minute-duration two-dimensional transmission scan followed by segmentation and reprojection. Scatter correction also was performed on all scans. After Fourier rebinning (FORE) of the three-dimensional data into two-dimensional data sets, scans were reconstructed with smoothing parameters selected that provided images for both scanners with in-plane and axial resolution of approximately $8.5 \mathrm{~mm}$ full-width at halfmaximum. Statistical checks showed that any residual scanner effects were negligible and had no substantive impact on any of the results or conclusions.

\section{Data Analysis}

The continuous infusion protocol for $\left[{ }^{11} \mathrm{C}\right] \mathrm{DTBZ}$ administration allows an equilibrium analysis to be performed. ${ }^{27}$ An index of the density of striatal presynaptic monoaminergic terminals was estimated as the distribution volume ratio (DVR) relative to occipital cortex, or equivalently as the normalized specific binding density called the binding potential (BP), which equals DVR-1. The occipital cortex served as a reference region containing negligible specific binding, thus reflecting the distribution volume of free plus nonspecifically bound $\left[{ }^{11} \mathrm{C}\right] \mathrm{DTBZ}$. DVR was measured in the caudate nucleus and in the anterior and posterior putamen using three-dimensional rectangular volumes of interest (VOIs) of $4.5 \times 9 \times 4.5 \mathrm{~mm}$. VOIs were centered on the areas of greatest DVR in the caudate nucleus, then moved successively 11 and $20 \mathrm{~mm}$ posteriorly, and recentered on the area of greatest DVR in the anterior and posterior putamen, respectively. Striatal binding values were calculated as the simple average of values in both hemispheres for each of the three regions. Percentage of asym- 
metry of binding was measured in each of the three striatal regions as the absolute difference in regional $\mathrm{BP}$ values in the right and left hemispheres divided by the mean of the two sides. Differences between patient and control mean $\mathrm{BP}$ values for striatal $(+)-\left[{ }^{11} \mathrm{C}\right] \mathrm{DTBZ}$ binding were examined by analysis of variance, and $t$ tests were used for pairwise comparisons. To adjust for age and sex, we included these variables as covariates in regression models of the striatal binding values on subject group. For regressions of asymmetry of binding, cases were weighted by their striatal binding values to allow for nonconstant variance.

\section{Results}

\section{Subject Group Comparisons}

The four groups did not differ in mean age $(p=$ 0.41 , but the $\mathrm{AD}$ group contained a higher proportion of women than the other groups (Table 1). Symptom duration was longer in the DLB/PD group than the other two patient groups. There was no difference between patient groups in either mean MMSE scores (see Table 1) or in other tests that sampled major categories of cognitive functions, including attention, language, visual-spatial ability, and memory $(p>0.35)$. The only difference found was in motor ability (see Table 1).

\section{Striatal (+)- $\left[{ }^{11} C\right]$ Dihydrotetrabenazine Binding}

The Figure contains the binding potential values for striatal $(+)-\left[{ }^{11} \mathrm{C}\right] \mathrm{DTBZ}$ binding of normal control subjects, $\mathrm{AD}$ patients, and DLB/AD and DLB/PD patients for the caudate nucleus, anterior putamen, and posterior putamen. The illustration shows a broader range of values in all three structures for the $\mathrm{AD}$ group in comparison with the normal control group, but no other difference. In contrast, values for both DLB groups are appreciably lower than the other two groups, with the DLB/PD generally lower than the DLB/AD group. Only a few DLB cases show overlap with either of the other groups, and no overlap occurs between the DLB and normal control groups in either anterior or posterior putamen.

Table 2 contains the age- and sex-adjusted mean and raw standard deviation of BP by striatal structure. In the caudate nucleus, anterior putamen, and posterior putamen, mean binding potential is decreased by 62 to $77 \%$ in the DLB/PD group and by 45 to $67 \%$ in the $\mathrm{DLB} / \mathrm{AD}$ group compared with $\mathrm{AD}$ and control groups ( $p<0.001$ in all cases). There is a marginal difference between DLB/AD and DLB/PD groups in the caudate nucleus only and no difference between control and $\mathrm{AD}$ groups. Table 2 shows a gradient of BP decline in both DLB groups relative to the control group across individual components of the striatum, with the greatest decline in the posterior putamen $(-70 \%)$, a smaller decline in the anterior putamen $(-64 \%)$, and the smallest decline, though still substantial, in the caudate nucleus $(-50 \%)$. These declines in the DLB groups relative to the control and $\mathrm{AD}$ groups are significant in all three striatal structures $(p<0.0001)$.

Table 3 shows the age- and sex-adjusted weighted mean and raw standard deviation of relative asymmetry of BP for normal control, $\mathrm{AD}$, and DLB groups by striatal structure. There are no significant differences between groups for the caudate nucleus and anterior putamen, but for the posterior putamen the DLB/AD group has a higher relative asymmetry than the control and $\mathrm{AD}$ groups $(p<0.03)$.

\section{Autopsy Verification of Diagnosis}

Three patients died between 18 and 40 months after study, including one in the DLB/AD group and two in

Table 1. Subject Characteristics

\begin{tabular}{llccc}
\hline Characteristic & \multicolumn{1}{c}{$\mathrm{NC}(\mathrm{n}=19)$} & $\mathrm{AD}(\mathrm{n}=25)$ & $\mathrm{DLB} / \mathrm{AD}(\mathrm{N}=14)$ & $\mathrm{DLB} / \mathrm{PD}(\mathrm{n}=6)$ \\
\hline Sex (M:F) & \multicolumn{1}{c}{$10: 9$} & $7: 18^{\mathrm{a}}$ & $11: 3$ & $4: 2$ \\
Age (yr) (range) & $69.1 \pm 7.6(55-86)$ & $69.3 \pm 9.1(52-85)$ & $73.4 \pm 5.1(65-80)$ & $71.5 \pm 11.2(54-81)$ \\
MMSE (range) & $29 \pm 1(26-30)$ & $15 \pm 7(2-27)$ & $17 \pm 6(8-29)$ & $18 \pm 9(6-26)$ \\
Symptom duration (yr) & Not applicable & $5 \pm 3(1-13)$ & $4 \pm 2(2-7)$ & $8 \pm 3^{\mathrm{b}}(5-13)$ \\
Motor functioning & Not applicable & $3.3 \pm 3.7(0-12)$ & $6.5 \pm 3.0^{\mathrm{c}, \mathrm{d}}(2-10)$ & $12.7 \pm 3.1^{\mathrm{c}, \mathrm{e}}(10-16)$ \\
\hline
\end{tabular}

Data include mean \pm standard deviation and range.

${ }^{1}$ Motor function established from family ratings of general motor ability with the motor subscale of the Inventory of Psychic and Somatic Complaints-Elderly.

${ }^{a}$ Larger proportion of women than men in this group than the other groups $(p<0.005)$.

${ }^{b}$ Longer symptom duration in DLB/PD than in the other groups $(p<0.01)$.

${ }^{\mathrm{c}}$ Greater impairment in DLB/AD than in $\mathrm{AD}(p=0.02)$.

${ }^{\mathrm{d}}$ Greater impairment in DLB/PD than in DLB/AD $(p=0.009)$

${ }^{\mathrm{e}} \mathrm{Greater}$ impairment in $\mathrm{DLB} / \mathrm{PD}$ than in $\mathrm{AD}(p<0.0001)$.

$\mathrm{NC}=$ normal control; $\mathrm{AD}=$ Alzheimer's disease; DLB/AD = patients with a diagnosis of dementia with Lewy bodies who developed parkinsonian symptoms simultaneously with or after the onset of dementia; DLB/PD = patients with a diagnosis of dementia with Lewy bodies who developed parkinsonian symptoms at least 1 year before dementia; MMSE = Mini-Mental State Examination. 


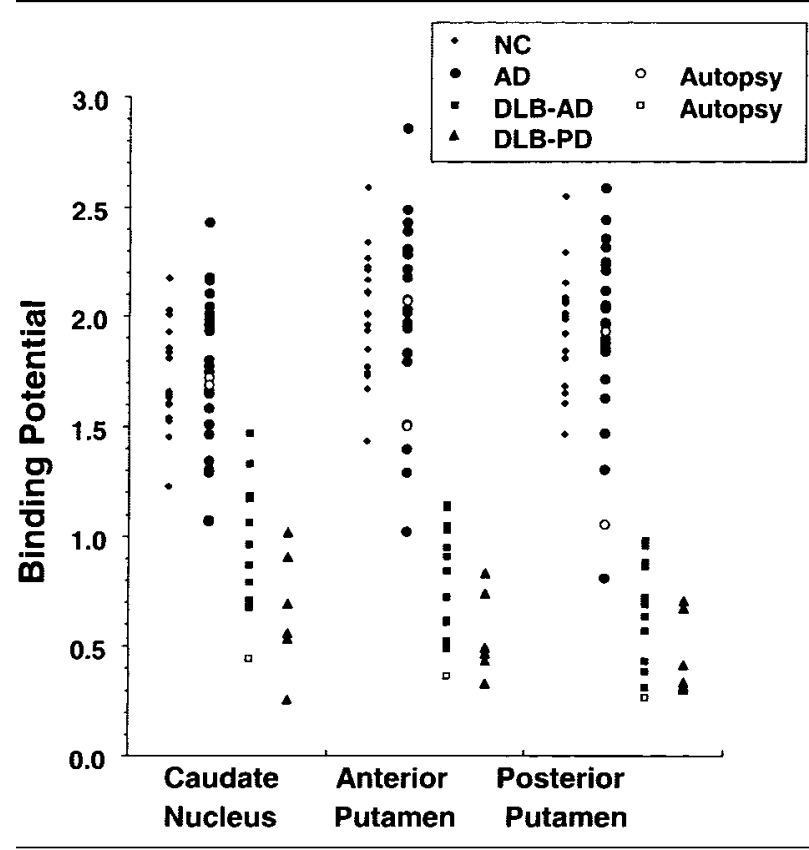

Fig. Binding potential values for striatal (+)- $\left[{ }^{11} C\right] D T B Z$ binding of normal control (NC) subjects, patients with Alzheimer's disease $(A D)$, patients with a diagnosis of dementia with Lewy bodies who developed parkinsonian symptoms at least 1 year before dementia (DLB/PD), and patients with a diagnosis of dementia with Lewy bodies who developed parkinsonian symptoms simultaneously with or after the onset of dementia (DLB/AD). Binding potential values are shown for the caudate nucleus, anterior putamen, and posterior putamen. Open symbols indicate the three patients who later came to postmortem examination. The lower of the two open symbols in the $A D$ columns indicates the patient who had neuropathological changes of both $A D$ and $D L B$.

the $\mathrm{AD}$ group. At neuropathological examination, the DLB/AD patient had changes typical of DLB without evidence of $\mathrm{AD}$. In this patient, the $\mathrm{BP}$ value was the second lowest of the DLB group in both the caudate nucleus and anterior putamen, and the lowest of the group in the posterior putamen (see Fig). One of the
$\mathrm{AD}$ patients had neuropathological changes characteristic of $\mathrm{AD}$ without evidence of $\mathrm{DLB}$, and the $\mathrm{BP}$ values in this case were approximately in the middle of the AD group for all three striatal structures. The second $\mathrm{AD}$ patient had neuropathological findings typical of both $\mathrm{AD}$ and $\mathrm{DLB}$, and the $\mathrm{BP}$ value was nearly normal in the caudate nucleus (11th lowest of 25) but was fourth lowest in the anterior putamen, and second lowest in the posterior putamen (see Fig). This patient showed no clinical evidence of parkinsonism at the time of study and died 18 months after participating. The patient was examined twice between the time of study and the time of death, and at the second examination 3 months before death the parkinsonian features of mild bradykinesia of face and body with mild rigidity of the limbs were found for the first time.

\section{Discussion}

This investigation disclosed significantly decreased striatal binding of $(+)-\left[{ }^{11} \mathrm{C}\right] \mathrm{DTBZ}$ in $\mathrm{DLB} / \mathrm{AD}$ and $\mathrm{DLB} / \mathrm{PD}$ patients as compared with both $\mathrm{AD}$ and normal control subjects and no difference between the latter two groups. Binding was significantly decreased in all three striatal structures of both DLB groups, with the largest decreases in the posterior putamen and progressively smaller decreases in the anterior putamen and caudate nucleus, respectively. Binding was marginally lower in the DLB/PD than in the DLB/AD group, with a significant difference only in the caudate nucleus. Significantly higher binding asymmetry between the two hemispheres was found for the DLB/AD group as compared with the other groups in the posterior putamen, but no group differences were found in the caudate nucleus or anterior putamen. The mean asymmetry values between the DLB/AD and DLB/PD groups were similar and the different significance values most likely reflect lesser power in the DLB/PD group because of fewer cases. Greater binding asymmetry has been reported in Parkinson's disease than in the present DLB cases. ${ }^{28,29}$ Parkinson's disease characteris-

Table 2. Mean and Standard Deviation of the Binding Potential for Each Striatal Structure after Adjustment for the Covariates of Age and Sex

\begin{tabular}{lcccc}
\hline & NC & AD & DLB/AD & DLB/PD \\
\hline Caudate nucleus & $1.73 \pm 0.23^{\mathrm{a}}$ & $1.75 \pm 0.35^{\mathrm{a}}$ & $0.95 \pm 0.29^{\mathrm{b}, \mathrm{c}}$ & $0.66 \pm 0.27^{\mathrm{b}, \mathrm{c}}$ \\
Anterior putamen & $2.00 \pm 0.27^{\mathrm{a}}$ & $2.07 \pm 0.41^{\mathrm{a}}$ & $0.80 \pm 0.25^{\mathrm{b}, \mathrm{d}}$ & $0.54 \pm 0.19^{\mathrm{b}, \mathrm{d}}$ \\
Posterior putamen & $1.94 \pm 0.25^{\mathrm{a}}$ & $1.94 \pm 0.42^{\mathrm{a}}$ & $0.65 \pm 0.23^{\mathrm{b}, \mathrm{d}}$ & $0.45 \pm 0.18^{\mathrm{b}, \mathrm{d}}$ \\
\hline
\end{tabular}

${ }^{a}$ No significant differences in group means $(p>0.48)$.

${ }^{\mathrm{b}}$ Means for DLB/PD and DLB/AD are lower than means for NC and AD groups $(p<0.001)$.

${ }^{\mathrm{c}}$ Mean for $\mathrm{DLB} / \mathrm{PD}$ is marginally lower than mean for $\mathrm{DLB} / \mathrm{AD}(p=0.05)$.

${ }^{\mathrm{d}}$ Means for DLB/PD and DLB/AD are not different $(p>0.1)$.

$\mathrm{NC}=$ normal control; $\mathrm{AD}=$ Alzheimer's disease; $\mathrm{DLB} / \mathrm{AD}=$ patients with a diagnosis of dementia with Lewy bodies who developed parkinsonian symptoms simultaneously with or after the onset of dementia; DLB/PD = patients with a diagnosis of dementia with Lewy bodies who developed parkinsonian symptoms at least 1 year before dementia. 
Table 3. Mean and Standard Deviation of the Percentage of Asymmetry of the Binding Potential of Striatal Structures after Adjustment for the Covariates of Age and Sex by Weighted ANCOVA

\begin{tabular}{lccrr}
\hline & NC (\%) & AD (\%) & DLB/AD (\%) & DLB/PD (\%) \\
\hline Caudate nucleus & $4.4 \pm 3.2^{\mathrm{a}}$ & $6.9 \pm 6.0^{\mathrm{a}}$ & $7.0 \pm 5.8^{\mathrm{a}}$ & $3.6 \pm 6.1^{\mathrm{a}}$ \\
Anterior putamen & $5.2 \pm 2.5^{\mathrm{a}}$ & $4.4 \pm 4.8^{\mathrm{a}}$ & $7.9 \pm 8.9^{\mathrm{a}}$ & $6.7 \pm 3.4^{\mathrm{a}}$ \\
Posterior putamen & $6.7 \pm 3.7^{\mathrm{a}, \mathrm{b}}$ & $4.8 \pm 8.3^{\mathrm{a}, \mathrm{b}}$ & $14.5 \pm 18.1^{\mathrm{b}, \mathrm{c}}$ & $16.5 \pm 12.6^{\mathrm{c}}$ \\
\hline
\end{tabular}

${ }^{a}$ No significant group difference in group means $(p>0.1)$.

${ }^{\mathrm{b}}$ Mean for DLB/AD is higher than means for NC and $\mathrm{AD}(p \leq 0.03)$.

${ }^{c}$ Means for DLB/PD and DLB/AD are not different $(p>0.8)$.

$\mathrm{NC}=$ normal control; $\mathrm{AD}=$ Alzheimer's disease; $\mathrm{DLB} / \mathrm{AD}=$ patients with a diagnosis of dementia with Lewy bodies who developed parkinsonian symptoms simultaneously with or after the onset of dementia; DLB/PD = patients with a diagnosis of dementia with Lewy bodies who developed parkinsonian symptoms at least 1 year before dementia.

tically shows marked asymmetry in both presynaptic terminals ${ }^{28}$ and dopaminergic D2 receptors, ${ }^{29}$ with the asymmetry correlated to the clinical findings.

We selected cases for study with established diagnoses by currently accepted clinical criteria. The purpose was to determine whether these studies would clearly separate the groups, and, if so, we planned to carry the study into patients with early dementia. The cases selected had equivalent levels of dementia and were well matched in age and duration of disease. The major difference between patient groups was the higher proportion of women in the $\mathrm{AD}$ than in the DLB group, reflecting in part the relative prevalence of these disorders in the two sexes. Other factors may have contributed to these differences, but we avoided systematic selection bias by accepting all patients who met diagnostic criteria and agreed to participate. All DLB patients fulfilled criteria for probable DLB according to consensus criteria, ${ }^{11}$ and all had clear parkinsonian features.

The finding of decreased striatal monoaminergic terminals in DLB was not surprising, because these patients all had identifiable features of parkinsonism, including bradykinesia, masked face, limb rigidity, and parkinsonian gait. Moreover, as anticipated, we found lower binding levels in the DLB patients whose disorders began with parkinsonian features initially in comparison with those whose disorders began with dementia. One surprising finding was that a few $\mathrm{AD}$ patients had binding values below the lower limit of the normal control group, notably in the posterior putamen. We obtained a postmortem examination in one of these cases and found changes typical of both DLB and AD. This patient exhibited no parkinsonian features at the time of study, and mild bradykinesia and rigidity were detected 15 months after the study, 3 months before death. This indicates that the decline in monoaminergic presynaptic terminals occurs well in advance of clinical evidence of parkinsonism and lends some credence to the possibility that in mild cognitive impairment or early dementia we may be able to differentiate
AD from DLB using PET with $(+)-\left[{ }^{11}\right.$ C]DTBZ. Neuropathology findings on a second patient from the $\mathrm{AD}$ group showed no changes typical of DLB and this subject had normal DTBZ binding.

Several published functional brain imaging studies of $\mathrm{AD}, \mathrm{PD}$, and $\mathrm{DLB}$ cases are relevant to the current investigation. The approaches used have included PET studies of local cerebral metabolic rates for glucose $\left(\right.$ lCMRglc),${ }^{30}$ single-photon emission computed tomography (SPECT) investigations of local cerebral blood flow, ${ }^{31}$ and both PET $^{32-35}$ and SPECT ${ }^{36-39}$ studies of nigrostriatal projections using ligands that label dopaminergic presynaptic or postsynaptic sites. Three studies examined striatal dopaminergic presynaptic terminals in various groups of cases that included $\mathrm{PD}, \mathrm{DLB}, \mathrm{AD}$ and normal age-appropriate controls using PET with the striatal dopaminergic presynaptic ligand $\left[{ }^{18} \mathrm{~F}\right]$ fluorodopa ${ }^{32-34}$ and one with the dopamine presynaptic reuptake ligand $\left[{ }^{11} \mathrm{C}\right] \beta$-CFT. ${ }^{35}$ One study using $\left[{ }^{18} \mathrm{~F}\right]$ fluorodopa in a small group of subjects reported results similar to those in the present investigation, that is, decreased uptake in the caudate nucleus and putamen in DLB as compared with $\mathrm{AD}$ and normal controls, and no difference between $\mathrm{AD}$ and control groups. ${ }^{32}$

The current investigation augments previous studies by showing a marked decrease of striatal binding in DLB, below the range of the normal control group and below the range of most $\mathrm{AD}$ patients. Moreover, our findings suggest that $\mathrm{AD}$ patients who have striatal binding below the range of the normal controls and in the upper range of the DLB cases may be developing the neuropathological changes of DLB in advance of clinical evidence of parkinsonism. This study shows in DLB patients a modest but significant asymmetry of binding in the posterior putamen but not in the caudate nucleus or anterior putamen. Additional studies will be needed to compare these findings with a group of PD patients with normal cognition to determine whether relative asymmetry of binding might be a useful means of determining whether a disorder that ap- 
pears to be PD may later evolve into DLB. Finally, the findings presented here suggest that PET with (+)$\left[{ }^{11} \mathrm{C}\right] \mathrm{DTBZ}$ may be used in patients with mild cognitive impairment or early dementia to differentiate those who will evolve to develop AD from those who will develop AD coupled with DLB. In this context, note that many patients have the combined pathology of $\mathrm{AD}$ and DLB. ${ }^{40,41}$

This work was supported by the NIH (National Institute of Neurological Disease and Stroke, P01 NS15655, S.D., R.A.K., R.L., M.H.; and National Institute on Aging, P50 AG08671, S.D., R.A.K., R.L., M.H., K.W.; and National Center for Research Resources, M01 RR00042, S.D.).

We thank Drs R. Albin, N. Barbas, N. L. Foster, D. Gelb, J. Heidebrink, K. Frey, and R. S. Turner for thoroughly evaluating and referring these patients to this study.

\section{References}

1. Heidebrink JL. Is dementia with Lewy bodies the second most common cause of dementia? J Geriatr Psych Neurol 2002;15: 182-187.

2. Gomez-Tortosa E, Newell K, Irizarry MC, et al. Alphasynuclein immunoreactivity in dementia with Lewy bodies: morphological staging and comparison with ubiquitin immunostaining. Acta Neuropathol 2000;99:352-357.

3. Gearing M, Lynn M, Mirra SS. Neurofibrillary pathology in Alzheimer disease with Lewy bodies: two subgroups. Arch Neurol 1999;56:203-208.

4. Galvin JE, Uryu K, Lee VM, Trojanowski JQ. Axon pathology in Parkinson's disease and Lewy body dementia hippocampus contains alpha-, beta-, and gamma-synuclein. Proc Natl Acad Sci USA 1999;96:13450-13455.

5. Schlossmacher MG, Frosch MP, Gai WP, et al. Parkin localizes to the Lewy bodies of Parkinson disease and dementia with Lewy bodies. Am J Path 2002;160:1655-1667.

6. Calderon J, Perry RJ, Erzinclioglu SW, et al. Perception, attention, and working memory are disproportionately impaired in dementia with Lewy bodies compared with Alzheimer's disease. J Neurol Neurosurg Psychiatry 2001;70:157-164.

7. Klatka LA, Louis ED, Schiffer RB. Psychiatric features in diffuse Lewy body disease: a clinicopathologic study using Alzheimer's disease and Parkinson's disease comparison groups. Neurology 1996;47:1148-1152.

8. Galasko D, Katzman R, Salmon DP, Hansen L. Clinical and neuropathological findings in Lewy body dementias. Brain Cogn 1996;31:166-175.

9. Chui HC, Lyness SA, Sobel E, Schneider LS. Extrapyramidal signs and psychiatric symptoms predict faster cognitive decline in Alzheimer's disease. Arch Neurol 1994;51:676-681.

10. Gnanalingham KK, Byrne EJ, Thornton A, et al. Motor and cognitive function in Lewy body dementia: comparison with Alzheimer's and Parkinson's diseases. J Neurol Neurosurg Psychiatry 1997;62:243-252.

11. McKeith IG, Galasko D, Kosaka K, et al. Consensus guidelines for the clinical and pathologic diagnosis of dementia with Lewy bodies (DLB): report of the consortium on DLB international workshop. Neurology 1996;47:1113-1124.

12. Litvan I, MacIntyre A, Goetz CG, et al. Accuracy of the clinical diagnoses of Lewy body disease, Parkinson disease, and dementia with Lewy bodies. Arch Neurol 1998;55:969-978.
13. Luis CA, Barker WW, Gajaraj K, et al. Sensitivity and specificity of three clinical criteria for dementia with Lewy bodies in an autopsy-verified sample. Int J Geriat Psychiatry 1999;14: $526-533$.

14. Lopez OL, Litvan I, Catt KE, et al. Accuracy of four clinical diagnostic criteria for the diagnosis of neurodegenerative dementias. Neurology 1999;53:1292-1299.

15. Verghese J, Crystal HA, Dickson DW, Lipton RB. Validity of clinical criteria for the diagnosis of dementia with Lewy bodies. Neurology 1999;53:1974-1982.

16. McKeith IG, Ballard CG, Perry RH, et al. Prospective validation of consensus criteria for the diagnosis of dementia with Lewy bodies. Neurology 2000;54:1050-1058.

17. Lopez OL, Becker JT, Kaufer DI, et al. Research evaluation and prospective diagnosis of dementia with Lewy bodies. Arch Neurol 2002;59:43-46.

18. McKhann G, Drachman D, Folstein M, et al. Clinical diagnosis of Alzheimer's disease: report of the NINCDS-ADRDA Work Group under the auspices of Department of Health and Human Services Task Force on Alzheimer's disease. Neurology 1984;34:939-944.

19. Rosen WG, Terry RD, Fuld PA, et al. Pathological verification of ischemic score in differentiation of dementia. Ann Neurol 1980;7:486-488.

20. Folstein MF, Folstein SE, McHugh PR. "Mini-mental state.” A practical method for grading the cognitive state of patients for the clinician. J Psychiatr Res 1975;12:189-198.

21. Wechsler D. Wechsler Adult Intelligence Scale. 3rd ed. San Antonio, TX: The Psychological Corporation, 1997.

22. Benton AL, Hamsher KDeS. Multilingual Aphasia Examination. 2nd ed. Iowa City, IA: AJA Associates, 1989.

23. Benton AL, Sivan AB, Hamsher KDeS, et al. Contributions to neuropsychological Assessment, a clinical manual. 2nd ed. New York: Oxford University Press, 1994.

24. Benedict RHB, Schretlen D, Groninger L, Brandt J. Hopkins Verbal Learning Test-Revised: normative data and analysis of inter-form and test-retest reliability. Clin Neuropsychol 1998; 12:43-55.

25. Raskin AS, Rae DS. Psychiatric symptoms in the elderly. Psychopharm Bull 1981;17:96-99.

26. Frey KA, Koeppe RA, Kilbourn MR, et al. Presynaptic monoaminergic vesicles in Parkinson's disease and normal aging. Ann Neurol 1996;40:873-884.

27. Koeppe RA, Frey KA, Kume A, et al. Equilibrium versus compartmental analysis for assessment of the vesicular monoamine transporter using $(+)-\alpha-\left[{ }^{11} \mathrm{C}\right]$ dihydrotetrabenazine (DTBZ) and PET. J Cereb Blood Flow Metab 1997;17:919-931.

28. Tatsch K, Schwarz J, Mozley PD, et al. Relationship between clinical features of Parkinson's disease and presynaptic dopamine transporter binding assessed with [123I]IPT and singlephoton emission tomography. Eur J Nucl Med 1997;24: 415-421.

29. Rinne JO, Laihinen A, Rinne UK, et al. PET study on striatal dopamine D2 receptor changes during the progression of early Parkinson's disease. Mov Disord 1993;8:134-138.

30. Minoshima S, Foster NL, Sima AA, et al. Alzheimer's disease versus dementia with Lewy bodies: cerebral metabolic distinction with autopsy confirmation. Ann Neurol 2001;50: $358-365$.

31. Lobotesis K, Fenwick JD, Phipps A, et al. Occipital hypoperfusion on SPECT in dementia with Lewy bodies but not AD. Neurology 2001;56:643-649.

32. Hu XS, Okamura N, Arai H, et al. 18F-fluorodopa PET study of striatal dopamine uptake in the diagnosis of dementia with Lewy bodies. Neurology 2000;55:1575-1577. 
33. Rinne JO, Portin R, Ruottinen $\mathrm{H}$, et al. Cognitive impairment and the brain dopaminergic system in Parkinson disease. $\left[{ }^{18} \mathrm{~F}\right]$ Fluorodopa positron emission tomography study. Arch Neurol 2000;57:470-475.

34. Ito K, Nagano-Saito A, Kato T, et al. Striatal and extrastriatal dysfunction in Parkinson's disease with dementia: a 6- $\left[{ }^{18}\right.$ F]fluoro-L-dopa PET study. Brain 2002;125:1358-1365.

35. Rinne JO, Sahlberg N, Ruottinen H, et al. Striatal uptake of the dopamine reuptake ligand $\left[{ }^{11} \mathrm{C}\right] \beta-\mathrm{CFT}$ is reduced in $\mathrm{Alz}-$ heimer's disease assessed by positron emission tomography. Neurology 1998;50:152-156.

36. Donnemiller E, Heilmann J, Wenning GK, et al. Brain perfusion scintigraphy with ${ }^{99 \mathrm{~m}} \mathrm{Tc}-\mathrm{HMPAO}$ or ${ }^{99 \mathrm{~m}} \mathrm{Tc}-\mathrm{ECD}$ and ${ }^{123}$ I- $\beta$-CIT single-photon emission tomography in dementia of the Alzheimer-type and diffuse Lewy body disease. Eur J Nucl Med 1997;24:320-325.
37. Ransmayrl G, Seppi K, Donnemiller E, et al. Striatal dopamine transporter function in dementia with Lewy bodies and Parkinson's disease. Eur J Nuc Med 2001;28:1523-1528.

38. Walker Z, Costa DC, Walker RW, et al. Differentiation of dementia with Lewy bodies from Alzheimer's disease using a dopaminergic presynaptic ligand. J Neurol Neurosurg Psychiatry 2002;73:134-140.

39. Walker Z, Costa DC, Janssen AG, et al. Dementia with Lewy bodies: a study of post-synaptic dopaminergic receptors with iodine-123 iodobenzamide single-photon emission tomography. Eur J Nucl Med 1997;24:609-614.

40. McKeith IG. Dementia with Lewy bodies. Br J Psychiatry 2002;180:144-147.

41. Lippa CF, McKeith I. Dementia with Lewy bodies: improving diagnostic criteria. Neurology 2003;60:1571-1573. 